\title{
Antidepressant Prescription Claims Among Reproductive-Aged Women With Private Employer-Sponsored Insurance — United States 2008-2013
}

\author{
April L. Dawson, $\mathrm{MPH}^{1}$; Elizabeth C. Ailes, $\mathrm{PhD}^{1}$; Suzanne M. Gilboa, $\mathrm{PhD}^{1}$; Regina M. Simeone, $\mathrm{MPH}^{1}$; Jennifer N. Lind, PharmD ${ }^{1}$; \\ Sherry L. Farr, $\mathrm{PhD}^{1}$; Cheryl S. Broussard, $\mathrm{PhD}^{1}$; Jennita Reefhuis, $\mathrm{PhD}^{1}$; Gerrard Carrino, $\mathrm{PhD}^{2}$; Janis Biermann, $\mathrm{MS}^{2}$; Margaret A. Honein, PhD ${ }^{1}$
}

Antidepressant medication use during pregnancy has been increasing in the United States (1). Many women require antidepressants on an ongoing basis, and a clear consensus on the safest medication options for both the mother and her fetus does not exist (2). Given that half of all U.S. pregnancies are unplanned (3), antidepressant use will occur during the first weeks of pregnancy, a critical period for fetal development. To understand trends among women of reproductive age, CDC used Truven Health's MarketScan Commercial Claims and Encounters data* to estimate the number of antidepressant prescriptions filled by women aged 15-44 years with private employer-sponsored insurance. During 2008-2013, an average of $15.4 \%$ of women aged 15-44 years filled at least one prescription for an antidepressant in a single year. The most frequently filled antidepressants included sertraline, bupropion, and citalopram. Prescribing of antidepressants is common, and research on antidepressant safety during pregnancy needs to be accelerated to provide evidence-based information to health care providers and women about the potential risks for antidepressant exposure before and during pregnancy and between pregnancies.

CDC used Truven Health's 2008-2013 MarketScan Commercial Claims and Encounters databases, a large convenience sample of employed persons and their dependents with private employer-sponsored insurance, to assess outpatient prescription drug claims for antidepressants. Demographic information is available for all persons enrolled in these private health insurance plans, regardless of whether or not the beneficiary seeks health care during a given year. In addition, all inpatient admissions, outpatient services, and outpatient pharmacy claims are available for each health care encounter.

\footnotetext{
* Proprietary data on inpatient services, outpatient services, and pharmacy claims provided by a convenience sample of commercial insurance providers (http://truvenhealth.com).
}

CDC analyzed data on women aged 15-44 years who had $\geq 11$ months of enrollment per calendar year in a private health insurance plan that included prescription drug coverage. Outpatient pharmacy claims were searched for antidepressant medications using national drug codes to determine whether women filled an antidepressant prescription during a given calendar year, regardless of the indication for use. The annual number, annual proportion, and overall average proportion of reproductive-aged women who filled an antidepressant prescription from an outpatient pharmacy were analyzed by

\section{INSIDE}

47 Increases in Acute Hepatitis B Virus Infections Kentucky, Tennessee, and West Virginia, 2006-2013

51 Active Monitoring of Travelers Arriving from EbolaAffected Countries — New York City, October 2014April 2015

55 Zika Virus Spreads to New Areas - Region of the Americas, May 2015-January 2016

59 Possible Association Between Zika Virus Infection and Microcephaly - Brazil, 2015

63 Interim Guidelines for the Evaluation and Testing of Infants with Possible Congenital Zika Virus Infection United States, 2016

68 Notes from the Field: Ongoing Cholera Outbreak Kenya, 2014-2016

70 Announcement

71 Notice to Readers

72 QuickStats

Continuing Education examination available at http://www.cdc.gov/mmwr/cme/conted_info.html\#weekly.

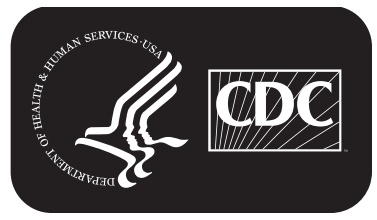

U.S. Department of Health and Human Services Centers for Disease Control and Prevention 
specific antidepressant medication and medication class, age group, and U.S. geographic region.

An average of 5.8 million privately insured reproductive-aged women (range $=4.6-6.8$ million) were included in the analytic sample each year during 2008-2013. During 2008-2013, on average, $15.4 \%$ of reproductive-aged women (range $=15.3 \%-15.6 \%$ ) filled a prescription for an antidepressant from an outpatient pharmacy each year; $76.0 \%$ filled prescriptions for only one type of antidepressant (Table). The most commonly filled antidepressant prescriptions by reproductive-aged women each year were for sertraline (filled by an average of $3.3 \%$ of reproductive-aged women each year), bupropion (2.7\%), citalopram (2.6\%), escitalopram $(2.5 \%)$, and fluoxetine (2.3\%) (Table). Overall, the percentage of reproductive-aged women with antidepressant claims remained relatively stable during 2008-2013; however, prescription claims for some antidepressants showed modest variability (Figure 1).

Variation in antidepressant claims by geographic region and age group was detected. A larger percentage of reproductiveaged women in the North Central and South regions of the United States filled an antidepressant prescription compared with women in the Northeast and West regions. By age group, the percentage of reproductive-aged women who filled a prescription for an antidepressant ranged from an average of $8.3 \%$ among women aged $15-19$ years to $20.9 \%$ among women aged 40-44 years (Table). However, among reproductive-aged women who filled prescriptions for common antidepressants (those filled by at least $0.5 \%$ of reproductive-aged women), the age distribution varied. Women aged 15-24 years represented
$12.5 \%$ of women filling prescriptions for duloxetine but $24.0 \%$ of women filling prescriptions for fluoxetine. There was less variation in the proportion of women filling an antidepressant who were aged 25-34 years, ranging from 26.8\% (for trazodone) to $32.9 \%$ (for sertraline). Women aged 35-44 years accounted for the largest proportion of reproductive-aged women filling prescriptions for all common antidepressant types, including $44.0 \%$ who filled prescriptions for sertraline and $60.3 \%$ who filled prescriptions for duloxetine (Figure 2).

\section{Discussion}

Approximately $15.4 \%$ of this convenience sample of reproductive-aged women with private employer-sponsored insurance filled a prescription for an antidepressant during 2008-2013. This relative frequency of dispensing of antidepressant prescriptions to this population raises public health concerns, given the high proportion of unplanned pregnancies, the lack of adequate information on the safety or risk of antidepressant use during pregnancy, and the reported possible association between the use of some antidepressants during early pregnancy and the occurrence of some major birth defects (1). There is some evidence of associations between early pregnancy use of paroxetine and five specific birth defects (anencephaly, gastroschisis, omphalocele, and selected cardiac defects, including atrial septal defects and right ventricular outflow tract obstruction defects), as well as two defects associated with fluoxetine use (right ventricular outflow tract obstruction defects and craniosynostosis) (1).

The MMWR series of publications is published by the Center for Surveillance, Epidemiology, and Laboratory Services, Centers for Disease Control and Prevention (CDC), U.S. Department of Health and Human Services, Atlanta, GA 30329-4027.

Suggested citation: [Author names; first three, then et al., if more than six.] [Report title]. MMWR Morb Mortal Wkly Rep 2016;65:[inclusive page numbers].

\author{
Centers for Disease Control and Prevention \\ Thomas R. Frieden, MD, MPH, Director \\ Harold W. Jaffe, MD, MA, Associate Director for Science \\ Joanne Cono, MD, ScM, Director, Office of Science Quality \\ Chesley L. Richards, MD, MPH, Deputy Director for Public Health Scientific Services \\ Michael F. Iademarco, MD, MPH, Director, Center for Surveillance, Epidemiology, and Laboratory Services
}

MMWR Editorial and Production Staff (Weekly)

Sonja A. Rasmussen, MD, MS, Editor-in-Chief

Charlotte K. Kent, $\mathrm{PhD}$, MPH, Executive Editor

Jacqueline Gindler, MD, Editor

Teresa F. Rutledge, Managing Editor

Douglas W. Weatherwax, Lead Technical Writer-Editor

Soumya Dunworth, PhD, Teresa M. Hood, MS, Technical Writer-Editors
Martha F. Boyd, Lead Visual Information Specialist Maureen A. Leahy, Julia C. Martinroe,

Stephen R. Spriggs, Moua Yang, Tong Yang, Visual Information Specialists

Quang M. Doan, MBA, Phyllis H. King,

Teresa C. Moreland, Terraye M. Starr, Information Technology Specialists
MMWR Editorial Board

Timothy F. Jones, MD, Chairman

Matthew L. Boulton, MD, MPH

Virginia A. Caine, MD

Katherine Lyon Daniel, PhD

Jonathan E. Fielding, MD, MPH, MBA

David W. Fleming, MD
William E. Halperin, MD, DrPH, MPH

King K. Holmes, MD, PhD

Robin Ikeda, MD, MPH

Rima F. Khabbaz, MD

Phyllis Meadows, PhD, MSN, RN

Jewel Mullen, MD, MPH, MPA
Jeff Niederdeppe, $\mathrm{PhD}$

Patricia Quinlisk, MD, MPH

Patrick L. Remington, MD, MPH

Carlos Roig, MS, MA

William L. Roper, MD, MPH

William Schaffner, MD 
TABLE. Number and percentage of reproductive-aged women* who filled a prescription for an antidepressant, by demographic characteristics and medication type - Truven Health MarketScan Commercial Claims and Encounters data, United States, 2008-2013

\begin{tabular}{|c|c|c|c|c|c|c|c|}
\hline & 2008 & 2009 & 2010 & 2011 & 2012 & 2013 & $\begin{array}{l}\text { Average } \\
2008-2013\end{array}$ \\
\hline Characteristic & No. $(\%)$ & No. (\%) & No. (\%) & No. (\%) & No. $(\%)$ & No. (\%) & $\%$ \\
\hline Total women ${ }^{\dagger}$ & $4,631,109(100)$ & $5,266,704(100)$ & $5,671,940(100)$ & $6,476,309(100)$ & $6,811,114(100)$ & $5,695,016(100)$ & $\mathrm{NA}^{\S}$ \\
\hline Any antidepressant prescription filled & $708,924(15.3)$ & $813,078(15.4)$ & $873,951(15.4)$ & $1,009,566(15.6)$ & $1,056,901(15.5)$ & $874,755(15.4)$ & 15.4 \\
\hline \multicolumn{8}{|l|}{ Age group (yrs) } \\
\hline $15-19$ & $59,945(7.5)$ & $69,743(7.7)$ & $77,625(7.8)$ & $93,468(8.3)$ & $103,604(8.9)$ & 91,937 (9.4) & 8.3 \\
\hline $20-24$ & $62,177(11.1)$ & $71,742(11.3)$ & $77,658(11.2)$ & $112,143(11.5)$ & $130,986(11.7)$ & $117,070(11.8)$ & 11.5 \\
\hline $25-29$ & $90,767(14.0)$ & $106,020(14.1)$ & $109,521(13.9)$ & $120,299(14.0)$ & $124,089(13.7)$ & $94,456(13.3)$ & 13.8 \\
\hline $30-34$ & $126,257(16.6)$ & $147,319(16.8)$ & $159,369(16.7)$ & $179,429(17.0)$ & $185,085(16.7)$ & $147,854(16.1)$ & 16.7 \\
\hline $35-39$ & $172,042(19.2)$ & $196,682(19.4)$ & $211,170(19.4)$ & $229,468(19.7)$ & $228,472(19.5)$ & $186,058(19.0)$ & 19.4 \\
\hline $40-44$ & $197,736(20.5)$ & $221,572(20.5)$ & $238,608(20.5)$ & $274,759(21.2)$ & $284,665(21.3)$ & $237,380(21.2)$ & 20.9 \\
\hline \multicolumn{8}{|l|}{ Region } \\
\hline Northeast & $66,128(13.8)$ & $79,069(13.1)$ & $107,847(14.1)$ & $147,961(14.7)$ & $163,054(14.9)$ & $134,460(14.0)$ & 14.2 \\
\hline North Central & $188,443(16.2)$ & $244,541(16.6)$ & $241,848(16.5)$ & $258,061(16.7)$ & $272,684(16.6)$ & $213,174(17.4)$ & 16.7 \\
\hline South & $339,799(15.9)$ & $367,782(16.0)$ & $372,593(16.2)$ & $422,960(16.3)$ & $420,343(16.2)$ & $331,520(16.1)$ & 16.1 \\
\hline West & $111,424(13.4)$ & 120,218 (13.6) & $148,987(13.2)$ & $157,329(13.1)$ & $184,872(13.3)$ & $167,196(13.0)$ & 13.3 \\
\hline Missing & $3,130(12.8)$ & $1,468(11.1)$ & $2,676(13.3)$ & $23,255(18.1)$ & $15,948(18.0)$ & $28,405(17.2)$ & 17.0 \\
\hline \multicolumn{8}{|l|}{ Specific antidepressants" } \\
\hline Any SSRI & $487,162(10.5)$ & $559,285(10.6)$ & $603,423(10.6)$ & $702,701(10.9)$ & $736,732(10.8)$ & $612,758(10.8)$ & 10.7 \\
\hline Citalopram & $90,439(2.0)$ & $121,572(2.3)$ & $148,932(2.6)$ & $195,292(3.0)$ & $196,904(2.9)$ & $144,590(2.5)$ & 2.6 \\
\hline Escitalopram & $139,915(3.0)$ & $146,292(2.8)$ & $141,053(2.5)$ & $142,047(2.2)$ & $155,965(2.3)$ & $149,225(2.6)$ & 2.5 \\
\hline Fluoxetine & $108,672(2.4)$ & $121,163(2.3)$ & $129,746(2.3)$ & $151,481(2.3)$ & $158,899(2.3)$ & $132,496(2.3)$ & 2.3 \\
\hline Fluvoxamine & $2,824(0.1)$ & $3,474(0.1)$ & $3,929(0.1)$ & $4,657(0.1)$ & $4,882(0.1)$ & $4,302(0.1)$ & 0.1 \\
\hline Paroxetine & $46,584(1.0)$ & $48,676(0.9)$ & $47,324(0.8)$ & $50,212(0.8)$ & $49,611(0.7)$ & $38,364(0.7)$ & 0.8 \\
\hline Sertraline & $142,052(3.1)$ & $168,946(3.2)$ & $187,223(3.3)$ & $222,186(3.4)$ & $235,716(3.5)$ & $196,352(3.5)$ & 3.3 \\
\hline Any SNRI & $136,578(3.0)$ & $157,010(3.0)$ & $163,630(2.9)$ & $181,154(2.8)$ & $180,029(2.6)$ & $141,301(2.5)$ & 2.8 \\
\hline Desvenlafaxine & $7,863(0.2)$ & $25,540(0.5)$ & $32,041(0.6)$ & $33,993(0.5)$ & $30,103(0.4)$ & $20,742(0.4)$ & 0.4 \\
\hline Duloxetine & $62,725(1.4)$ & $68,022(1.3)$ & $68,162(1.2)$ & $74,796(1.2)$ & $73,802(1.1)$ & $56,073(1.0)$ & 1.2 \\
\hline Milnacipran & $N A^{* *}$ & $3,091(0.1)$ & $5,677(0.1)$ & $6,089(0.1)$ & $5,127(0.1)$ & $3,392(0.1)$ & 0.1 \\
\hline Venlafaxine & $72,469(1.6)$ & $69,873(1.3)$ & $66,960(1.2)$ & $75,967(1.2)$ & $80,054(1.2)$ & $67,893(1.2)$ & 1.3 \\
\hline Any Tricyclic & $63,336(1.4)$ & $74,558(1.4)$ & $80,365(1.4)$ & $95,100(1.5)$ & $100,704(1.5)$ & $82,764(1.5)$ & 1.4 \\
\hline Amitriptyline & $40,277(0.9)$ & $47,253(0.9)$ & $50,993(0.9)$ & $59,056(0.9)$ & $63,134(0.9)$ & $51,202(0.9)$ & 0.9 \\
\hline Any MAOI & $420(0)$ & $422(0)$ & $435(0)$ & $484(0)$ & $470(0)$ & $419(0)$ & 0 \\
\hline Any Other & $172,295(3.7)$ & $197,719(3.8)$ & $216,320(3.8)$ & 252,159 (3.9) & $272,318(4.0)$ & $230,147(4.0)$ & 3.9 \\
\hline Bupropion & $126,812(2.7)$ & $145,163(2.8)$ & $153,627(2.7)$ & $174,711(2.7)$ & $181,636(2.7)$ & $151,873(2.7)$ & 2.7 \\
\hline Trazodone & $47,901(1.0)$ & $55,641(1.1)$ & $66,639(1.2)$ & $79,737(1.2)$ & $87,589(1.3)$ & $75,494(1.3)$ & 1.2 \\
\hline $\begin{array}{l}\text { Filled only one prescription for an } \\
\text { antidepressant }\end{array}$ & $127,619(2.8)$ & $145,864(2.8)$ & $154,523(2.7)$ & $174,900(2.7)$ & $182,358(2.7)$ & $145,278(2.6)$ & 2.7 \\
\hline $\begin{array}{l}\text { Filled prescription(s) for only one type } \\
\text { of antidepressant }^{\dagger+}\end{array}$ & $541,820(11.7)$ & $617,605(11.7)$ & $662,792(11.7)$ & 764,441 (11.8) & 799,599 (11.7) & $662,501(11.6)$ & 11.7 \\
\hline $\begin{array}{l}\text { Filled prescriptions for multiple } \\
\text { antidepressant types } \S \S\end{array}$ & $167,104(3.6)$ & $195,473(3.7)$ & 211,159 (3.7) & 245,125 (3.8) & $257,302(3.8)$ & $212,254(3.7)$ & 3.7 \\
\hline
\end{tabular}

Abbreviations: $\mathrm{MAOI}=$ monoamine oxidase inhibitor; $\mathrm{NA}=$ not applicable; SNRI = serotonin and norepinephrine reuptake inhibitors; SSRI = selective serotonin reuptake inhibitors.

* Women aged 15-44 years, who were enrolled for $\geq 11$ months of the year in a private health plan with prescription drug coverage.

t The same woman might have been included in multiple years of data.

$\S$ Average percentage during the study period is not a relevant calculation when looking at the total population.

" Not mutually exclusive.

** Milnacipran was not approved by the U.S. Food and Drug Administration until 2009.

${ }^{+\dagger}$ Includes women with claims for only one specific type of antidepressant during the calendar year.

$\S \S$ Includes medications filled concurrently or separately during the same calendar year.

Approximately $30 \%$ of reproductive-aged women had current depression or had ever received a clinical diagnosis of a depressive or anxiety disorder, based on 2006 data from the Behavioral Risk Factor Surveillance System, and these conditions often went untreated (4). Although rates of self-reported depression were similar among white and nonwhite women, the rates of clinical diagnosis and treatment were lower among nonwhite women (4). Depressed women have higher rates of smoking, binge or heavy drinking, obesity, and physical inactivity, which might also pose risks to a developing fetus during pregnancy (5). It is important for all women to be screened for depression, including pregnant women and women who have recently given birth (G). Ideally, women and their health care providers should discuss treatment options for depression in advance of pregnancy and choose the treatment course that is best for both the mother 
FIGURE 1. Proportion of reproductive-aged women* who filled a prescription $^{\dagger}$ for one of the most common antidepressant types, $\$$ by year - Truven Health MarketScan Commercial Claims and Encounters data, 2008-2013

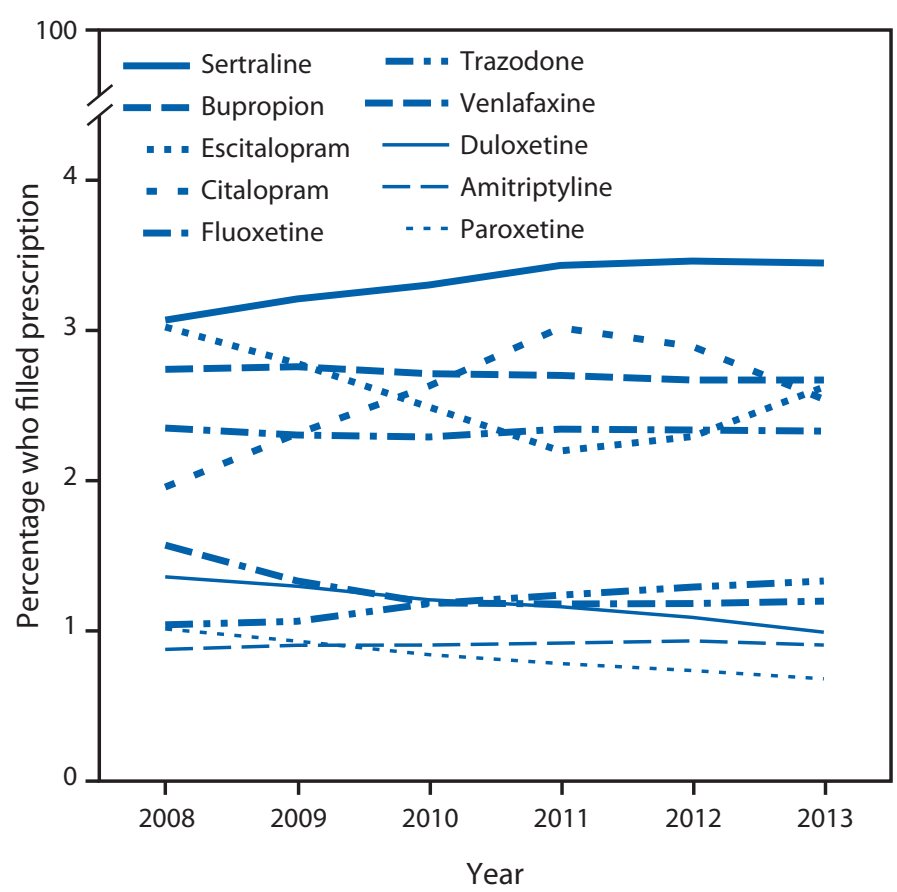

* Women aged 15-44 years who were enrolled in a private health plan that included prescription drug coverage for $\geq 11$ months of the year.

† Women could have filled prescriptions for more than one medication type.

$\S$ Selective serotonin reuptake inhibitors include sertraline, escitalopram, citalopram, fluoxetine, and paroxetine. Serotonin and norepinephrine reuptake inhibitors include venlafaxine and duloxetine. Amitriptyline is a tricyclic antidepressant. Other antidepressants include bupropion and trazodone.

and the baby, which could include medication, but could also include other types of treatment such as counseling.

Published studies examining antidepressant use specifically among women of reproductive age are limited, and none describe antidepressant use in the same interval as the current study (i.e., use in a given year). Analysis of nationally representative data from the 2005-2008 National Health and Nutrition Examination Survey determined that $9 \%$ of women aged 18-39 years reported taking an antidepressant medication during the preceding month, and that antidepressant use increased significantly with increasing age ( 7 ). Other studies have used health insurance claims data to assess antidepressant use among pregnant women $(8,9)$. These studies have also provided estimates of prepregnancy use, which might provide a basis for comparison with the estimate in this report. Antidepressant use was higher before pregnancy than during or after pregnancy $(8,9)$. A study of approximately 343,000 privately insured women with pregnancies during 2006-2011 using Truven Health MarketScan Commercial Claims and Encounters databases reported that $9.9 \%$ of pregnant women

\section{Summary}

What is already known on this topic?

Antidepressant use is relatively common among women of reproductive age, and the use of certain antidepressants during early pregnancy are possibly associated with the occurrence of some major birth defects. Multiple treatment options can be considered for reproductive-aged women with depression and related disorders. Given that half of all U.S. pregnancies are unplanned, use of antidepressants will occur during the first weeks of pregnancy, a critical period for fetal development.

What is added by this report?

During 2008-2013, approximately $15 \%$ of a convenience sample of reproductive-aged women (aged 15-44 years) with employersponsored insurance filled a prescription for antidepressants. The most commonly filled antidepressants were sertraline, bupropion, and citalopram. Women aged 35-44 years accounted for the largest proportion of reproductive-aged women filling prescriptions for all common antidepressant types.

What are the implications for public health practice?

Antidepressant use is common among women of reproductive age, and research on antidepressant safety during pregnancy needs to be accelerated to provide evidence-based information for health care providers so they can effectively weigh the risks and benefits of treatment options in reproductive-aged women who are planning to or could become pregnant.

filled a prescription for an antidepressant in the 6 months before conception, and $6.5 \%$ filled a prescription for an antidepressant at any point during pregnancy (8). An analysis of antidepressant prescriptions filled by approximately 1.1 million pregnant women with Medicaid coverage during 2000-2007 determined that 6.5\% of pregnant women filled a prescription for an antidepressant in the 90 days before their last menstrual period, and $8.1 \%$ filled a prescription during pregnancy (9). In these two reports, antidepressant claims typically decreased to slightly less than $4 \%$ during the second and third trimesters of pregnancy, possibly because the women stopped treatment after learning they were pregnant.

The findings in this report are subject to at least four limitations. First, although this analysis included approximately 5-7 million reproductive-aged women each year, these data are a convenience sample of privately insured women and might not be generalizable across other populations. Approximately $50 \%$ of births in the United States occur to women with Medicaid coverage (10), and previous studies have suggested that antidepressant use might be higher in this population (9). In addition, an average of 2.6 million women (range $=2.1-2.9$ million) were excluded from each year of the analysis because they were enrolled for $<11$ months during the calendar year. Restricting the analysis to women who were enrolled for $\geq 11$ months during a calendar year might have increased the likelihood that the sample would include 
FIGURE 2. Age distribution of reproductive-aged women* who filled a prescription ${ }^{\dagger}$ for an antidepressant, by antidepressant type Truven Health MarketScan Commercial Claims and Encounters data, 2008-2013

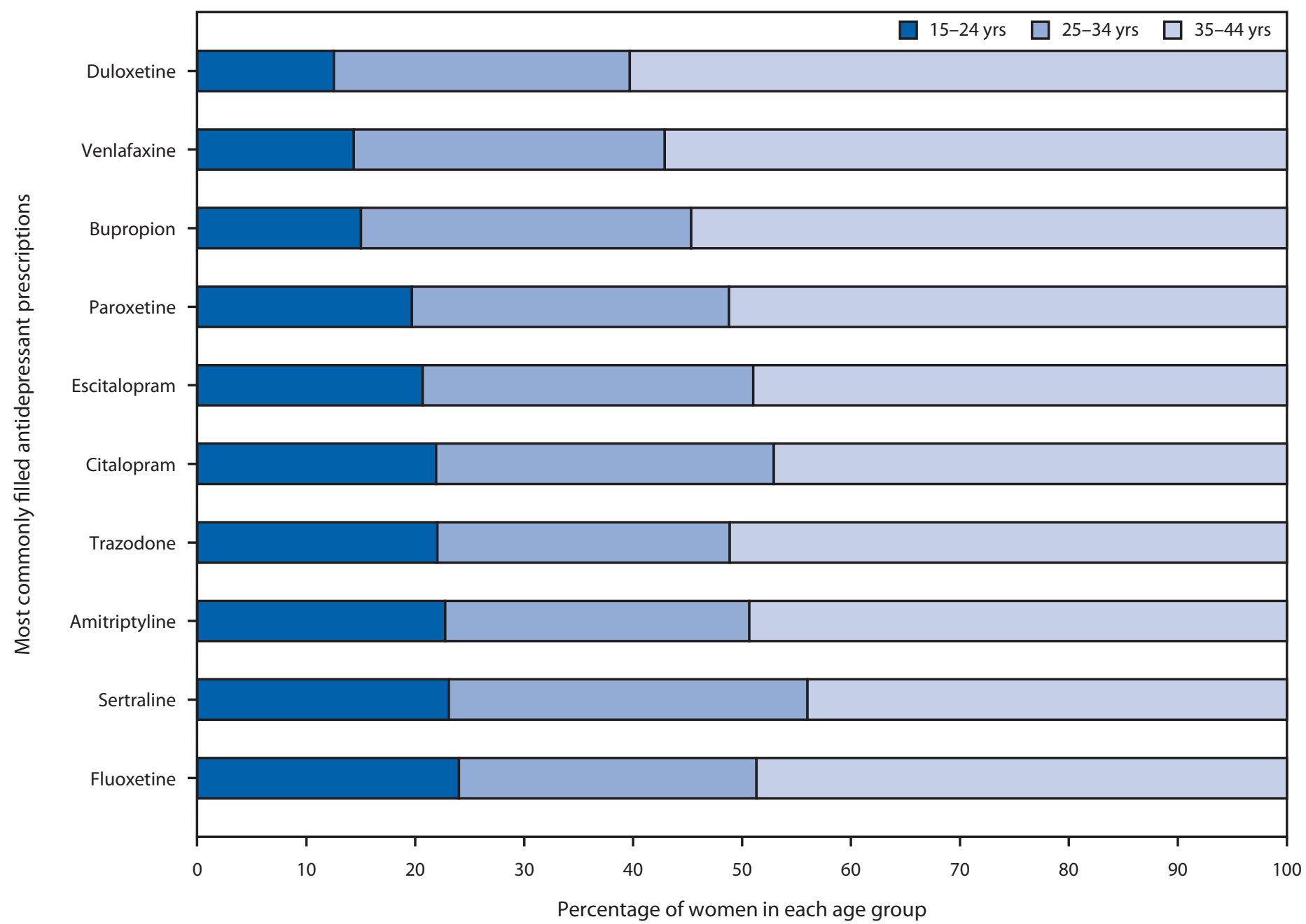

\footnotetext{
* Women aged 15-44 years who were enrolled in a private health plan that included prescription drug coverage for $\geq 11$ months of the year and who filled a prescription for the most common antidepressant medications.

† Women could have filled prescriptions for more than one medication type.
}

women with a health condition requiring treatment (11). Second, the number and type of health plans included in the database have changed over time; therefore, caution must be exercised in analyzing time trends. Third, no information was available about women who paid for their prescriptions in cash or obtained free samples, or about whether women took the dispensed antidepressants. Finally, this analysis did not identify women who were pregnant or ascertain whether antidepressant prescription claims were limited to women who were infertile or using contraception; an estimated $62 \%$ of women of reproductive age use contraception. ${ }^{\dagger}$

This analysis used a large, geographically diverse database to estimate the proportion of privately insured reproductive-aged women who filled a prescription for an antidepressant from an outpatient pharmacy. The high prevalence of antidepressant claims in this population highlights the need for more research to support development of evidence-based guidance for informed decision making by health care providers and reproductiveaged women. To help address this need, CDC's Treating for Two: Safer Medication Use in Pregnancy Initiative $\mathbb{S}^{\mathbb{a}}$ aims to accelerate research on antidepressant safety during pregnancy to provide evidence-based information for health care providers to effectively weigh the risks and benefits of treatment options for reproductive-aged women who could become pregnant.

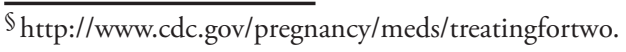

\footnotetext{
${ }^{\dagger}$ http://www.cdc.gov/nchs/data/nhsr/nhsr060.pdf.
} 
${ }^{1}$ Division of Birth Defects and Developmental Disabilities, National Center on Birth Defects and Developmental Disabilities, CDC; ${ }^{2}$ March of Dimes Foundation, White Plains, New York.

Corresponding author: April Dawson, ALDawson@cdc.gov, 404-498-3912.

\section{References}

1. Reefhuis J, Devine O, Friedman JM, Louik C, Honein MA; National Birth Defects Prevention Study. Specific SSRIs and birth defects: Bayesian analysis to interpret new data in the context of previous reports. BMJ 2015;351:h3190. http://dx.doi.org/10.1136/bmj.h3190.

2. McDonagh MS, Matthews A, Phillipi C, et al. Depression drug treatment outcomes in pregnancy and the postpartum period: a systematic review and meta-analysis. Obstet Gynecol 2014;124:526-34. http://dx.doi. org/10.1097/AOG.0000000000000410.

3. Finer LB, Zolna MR. Shifts in intended and unintended pregnancies in the United States, 2001-2008. Am J Public Health 2014;104(Suppl 1):S43-8. http://dx.doi.org/10.2105/AJPH.2013.301416.

4. Farr SL, Bitsko RH, Hayes DK, Dietz PM. Mental health and access to services among US women of reproductive age. Am J Obstet Gynecol 2010;203:542e.1-9.
5. Farr SL, Hayes DK, Bitsko RH, Bansil P, Dietz PM. Depression, diabetes, and chronic disease risk factors among US women of reproductive age. Prev Chronic Dis 2011;8:A119.

6. Siu AL; US Preventive Services Task Force. Screening for depression in adults. US Preventive Task Force Recommendation Statement. JAMA 2016:315:380-387

7. Pratt LA, Brody DJ, Gu Q. Antidepressant use in persons aged 12 and over: United States, 2005-2008. NCHS Data Brief 2011;76:1-8.

8. Hanley GE, Mintzes B. Patterns of psychotropic medicine use in pregnancy in the United States from 2006 to 2011 among women with private insurance. BMC Pregnancy Childbirth 2014;14:242. http:// dx.doi.org/10.1186/1471-2393-14-242.

9. Huybrechts KF, Palmsten K, Mogun H, et al. National trends in antidepressant medication treatment among publicly insured pregnant women. Gen Hosp Psychiatry 2013;35:265-71. http://dx.doi. org/10.1016/j.genhosppsych.2012.12.010.

10. Curtin SC, Osterman MJ, Uddin SF, Sutton SR, Reed PR. Source of payment for the delivery: births in a 33-state and District of Columbia reporting area, 2010. Natl Vital Stat Rep 2013;62:1-20.

11. Jensen ET, Cook SF, Allen JK, et al. Enrollment factors and bias of disease prevalence estimates in administrative claims data. Ann Epidemiol 2015;25:519-525.e2. http://dx.doi.org/10.1016/ j.annepidem.2015.03.008. 